\title{
The resistance training effects of different weight level during menstrual cycle in female
}

\author{
Eun-Sook Sung', Jung-Hyun Kim ${ }^{2 * *}$ \\ 'Department of Graduate School of Alternative Medicine, Kyonggi University, Seoul, Korea \\ ${ }^{2}$ Department of Physical Therapy, College of Health Welfare, Woosong University, Daejeon, Korea
}

We examined the different effects of body mass index (BMI) level on resistance training during menstrual cycle. Thirty-six female subjects performed resistance training and subjects were divided into three groups: $\mathrm{BMI}_{\text {under, }} \mathrm{BMI}_{\text {norm, }} \mathrm{BMI}_{\text {over. }}$ Subjects completed 12 weeks of submaximal resistance training with 3 sets of 8-12 repetitions. Maximum isometric force test was measured before and after training in the follicular phase (FP) and the luteal phase (LP). Maximum isometric force of whole groups ( $\mathrm{BMI}_{\text {under, }} \mathrm{BMI}_{\text {norm, }} \mathrm{BMI}_{\text {over }}$ ) was significantly increased both FP and LP after 12-week resistance training. Maximum isometric force after training and absolute increase value in $\mathrm{BMI}_{\text {norm }}$ and $\mathrm{BMI}_{\text {over }}$ were no significantly different between FP and LP. However, significant different of maximum isometric force after training (FP, $79.08 \pm 11.60$; LP, $84.05 \pm 12.38$ ) and absolute increase value (FP, $9.63 \pm 5.47 ; \mathrm{LP}, 15.13 \pm 6.06$ )

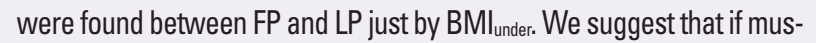
cle strength is measured in the FP (LP) before training and then they should be measured same phase, such as FP and LP after training and $\mathrm{BMI}_{\text {under }}$ can be influenced muscle strength in LP.

Keywords: Body mass index, Menstrual cycle, Resistance training

\section{INTRODUCTION}

In recent decades, the numbers of female participating in recreational exercise and elite athletic sports and competition have dramatically increased (Costello et al., 2014; Javed et al., 2013). Female are known to have the same physiological abilities as males and to be able to tolerate and adapt to heavy resistance training (Wang et al., 1993). The menstrual cycle, with its monthly hormonal fluctuations, is one of the most basic characteristics of female. Hence, many studies have focused on the possible effects of steroid hormone fluctuations in female's performance (Javed et al., 2013). The anabolic effect of the steroid testosterone is well known in males (Kraemer and Ratamess, 2005). However, the influence of the female sex steroid estrogen and progesterone on muscle strength and performance is not entirely clear and the available results are inconsistent (Bruinvels et al., 2016). In this context, a better understanding of the effects of cyclic variations in hormones and their impact on training in eumenorrheic female is needed.
The fact that female hormones influence muscle strength is evident by the hormone replacement therapy during postmenopausal periods (Barros and Gustafsson, 2011), especially by estrogens, suggesting that estrogens and progesterone are important modulators of muscle physiology on muscle strength (Greising et al., 2009). Furthermore, the beneficial effect of estrogens on muscle strength is accomplished by improving the intrinsic quality of skeletal muscles, whereby muscle fibers (type II) get enabled to generate force, i.e., myosin strongly binds to actin during contraction (Lowe et al., 2010; Velders et al., 2012; Weigt et al., 2012). Therefore, estrogen can induce an increase in muscle strength, including muscle fiber cross sectional area and muscle fiber composition (Enea et al., 2011).

In contrast to the seemingly catabolic stimulation of protein metabolism in the luteal phase (LP) and they suggested a positive influence of estrogen in reducing protein oxidation (Miller et al., 2006). Another study examined the rate of myofibrillar and connective tissue protein synthesis following one-legged kicking ex-
${ }^{*}$ Corresponding author: Jung-Hyun Kim (D) https://orcid.org/0000-0002-4710-8145 Department of Physical Therapy, College of Health Welfare, Woosong University, 171 Dongdaejeon-ro, Dong-gu, Daejeon 34606, Korea E-mail: junghyunkim9144@gmail.com

Received: January 29, 2019 / Accepted: March 28, 2019
This is an Open Access article distributed under the terms of the Creative Commons Attribution Non-Commercial License (http://creativecommons.org/licenses/by-nc/4.0/) which permits unrestricted non-commercial use, distribution, and reproduction in any medium, provided the original work is properly cited. 
ercise in two groups of eumenorrhoeic female. No differences were found between phases (Miller et al., 2006). Therefore, it appears that progesterone is responsible for the consistent finding of increased protein catabolism in the LP (Kriengsinyos et al., 2004), while estrogen may reduce protein catabolism (Hamadeh et al., 2005). Many results are not consistent across studies and, up to now, numerous guidelines for the progress of resistance training have been made available; however, these guidelines mostly stem from the research on the relationship between steroid hormone fluctuation during the menstrual cycle (follicular phase [FP] and LP) and strength (Constantini et al., 2005; Lebrun, 1994; Janse de Jonge, 2003). Many researchers investigated separately relationship between the muscle strength and body mass index (BMI) level and very few investigators have reported association muscle strength with various BMI level. Moreover, there are very few studies of young female and young female athlete. Lad et al. (2013) reported the subjects with underweight have low muscle strength, it can be explained on the basis of the energy deficiency. Other studies have stated that overweight or obese persons can have a fatty infiltration in the muscle fiber and different distribution of the type 1 and type 2 muscle fibers, which will change the muscle strength and endurance capacity (Hulens et al., 2001; Mak et al., 2010; Pieterse et al., 2002). However, up to now, the relationship of muscle strength/endurance in the overweight/obese population has yet to be clearly explained (Hulens et al., 2001; Mak et al., 2010) and no scientific publication investigated a possible relationship between strength and BMI level during menstrual cycle in FP and LP. In the present study, we aimed to examine the effects of resistance training in FP and LP on mucle strength according to BMI level.

\section{MATERIALS AND METHODS}

\section{Subject}

Thirty-six female subjects in eumenorrheic healthy (non-OC) were participated in this study and our study were divided groups (BMI $\mathrm{Bnder}_{\text {und }}, \mathrm{BMI}_{\text {norm }}$, and $\left.\mathrm{BMI}_{\text {over }}\right)$. $\mathrm{BMI}_{\text {under }}(\mathrm{n}=8)$ were recruited, with a mean age of $26.25 \pm 6.16$ years (height, $166.25 \pm 4.03 \mathrm{~cm}$; weight, $49.75 \pm 1.91 \mathrm{~kg}$; BMI, $\left.18.00 \pm 0.28 \mathrm{~kg} / \mathrm{m}^{2}\right) . \mathrm{BMI}_{\text {norm }}(\mathrm{n}=$ 22) were recruited, with a mean age of $25.45 \pm 4.13$ years (height, $162.64 \pm 5.49 \mathrm{~cm}$; weight, $59.77 \pm 5.33 \mathrm{~kg}$; BMI, $22.58 \pm 1.24$ $\left.\mathrm{kg} / \mathrm{m}^{2}\right) . \mathrm{BMI}_{\text {over }}(\mathrm{n}=6)$ were recruited, with a mean age of $26.5 \pm$ 7.37 years (height, $166.33 \pm 2.88 \mathrm{~cm}$; weight, $75.33 \pm 4.03 \mathrm{~kg}$; BMI, $27.19 \pm 0.92 \mathrm{~kg} / \mathrm{m}^{2}$ ) (Table 1). In three BMI ranges of underweight (BMI $\left.\leq 18.49 \mathrm{~kg} / \mathrm{m}^{2}\right)$, normal weight $(\mathrm{BMI}=18.5$
Table 1. General characteristics of subjects $(n=36)$

\begin{tabular}{lrrr}
\hline Characteristic & $\mathrm{BMl}_{\text {under }}(\mathrm{n}=8)$ & $\mathrm{BMI}_{\text {norm }}(\mathrm{n}=22)$ & $\mathrm{BMl}_{\text {over }}(\mathrm{n}=6)$ \\
\hline Age $(\mathrm{yr})$ & $26.25 \pm 6.16$ & $25.45 \pm 4.13$ & $26.50 \pm 7.37$ \\
Height $(\mathrm{cm})$ & $166.25 \pm 4.03$ & $162.64 \pm 5.49$ & $166.33 \pm 2.88$ \\
Weight $(\mathrm{kg})$ & $49.75 \pm 1.91$ & $59.77 \pm 5.33$ & $75.33 \pm 4.03$ \\
Body mass index $\left(\mathrm{kg} / \mathrm{m}^{2}\right)$ & $18.00 \pm 0.28$ & $22.58 \pm 1.24$ & $27.19 \pm 0.92$
\end{tabular}

Values are presented as mean \pm standard deviation.

$\mathrm{BMl}$, body mass index; $\mathrm{BMl} \mathrm{under}_{\mathrm{B}} \mathrm{BMl}<18.5 \mathrm{~kg} / \mathrm{m}^{2} ; \mathrm{BMI}_{\text {nom }}, 18.5 \mathrm{~kg} / \mathrm{m}^{2} \leq \mathrm{BMl}<25$ $\mathrm{kg} / \mathrm{m}^{2} ; \mathrm{BM} \mathrm{Blover}_{\mathrm{B}} \mathrm{BMl} \geq 25 \mathrm{~kg} / \mathrm{m}^{2}$.

$\left.24.99 \mathrm{~kg} / \mathrm{m}^{2}\right)$ and overweight $\left(\mathrm{BMI}=25.0-29.99 \mathrm{~kg} / \mathrm{m}^{2}\right)$. The subjects participated in this study and were selected from the following inclusion criteria: healthy female without neurological or movement disorder, nonsmokers, regular menstruation. They taken not other medications that might interfere hormone levels and sedentary or recreationally active. The female entering the study had not been without oral contraceptives for at least past 1 year. All subjects have taken their written informed consent before the study. Approval for the experimental protocol was obtained from the Ethics Committee of the Woosong University, Korea (approval number: 1041549-17024-SB-56-02).

\section{Menstrual cycle monitoring with basal body temperature}

The fluctuation of basal body temperature was used to identify ovulation and phases of the menstrual cycle in order to determine the training and testing schedule. The subjects were instructed to measure their basal body temperature every day with an electronic clinical thermometer orally for $1 \mathrm{~min}$, every morning at the time between 8:00 a.m. and 8:30 a.m. before rising from bed. Ovulation was indicated by a sustained increase in basal body temperature for at least $0.3^{\circ} \mathrm{C}$ (Albertson and Zinaman, 1987; Kelly, 2006; Owen, 1975). Temperature was suggested as an ovulation indicator and defined as the low point in the temperature curve seen at the base of the rise to the hyper-thermic phase (de Mouzon et al., 1984).

\section{Resistance training}

The subjects completed 12-week resistance training program. The training was performed 3 times a week (typically on Monday, Wednesday, and Friday) under supervision on a leg extension (selection pro-leg extension, Technogym, Neu-Isenburg, Germany) and once a week (typically on Saturday) at home with the subject's own body weight. On the leg extension subjects performed a submaximum resistance training (about $85 \%$ of maximum strength) with 3 sets of 8-12 repetitions until exhaustion with 2 min of recovery between sets. The respective weight on the leg extension 
machine was increased by $10 \mathrm{~kg}$ in the following training session if the subject was able to perform more than 12 repetitions during the last of the three sets. The resistance training program started individually with the 1st day of own menses. FP-based resistance training was trained eight times in FP and around ovulation (from 1st day of menses until ovulation) and just twice in LP (after ovulation until next menses). LP-based resistance training was trained 8 times in LP and just twice in FP.

\section{Maximum isometric force}

The maximum isometric force (MIF) measurement was determined on a leg extension (selection pro-leg extension, Technogym) using a combined force and load cell (KD80s, ME-Messsysteme GmbH, Hennigsdorf, Germany). MIF was measured separately once in late FP (day 11 from 1st menses) and once in the late LP (day 25 from 1st menses) before and after training intervention. Before the subjects take a testing underwent a 10-min warm-up with low-resistance (60\% from maximum oxygen uptake) ergometer cycling and they were familiarized with the test. The testing position (knee angle: $90^{\circ}$, ankle angle: $90^{\circ}$ ) separately with machine with leg extension. Each test was repeated 3 times with $30 \mathrm{sec}$ of recovery time between the tests. The best result was selected for data analysis and the intraclass correlation coefficient was 0.998 , which indicates that the system has a high internal consistency.

\section{Statistical analysis}

IBM SPSS Statistics ver. 22.0 (IBM Co., Armonk, NY, USA) was used for statistical analysis in this study. Increase of maximum isometric force and absolute value were analyzed before and after resistance training in the $\mathrm{FP}$ and in the $\mathrm{LP}$ among $\mathrm{BMI}_{\text {under, }} \mathrm{BMI}_{\text {norm }}$, $\mathrm{BMI}_{\text {over }}$ groups with using a Wilcoxon Matched-Pairs SignedRanks Test. The significance was set to $P<0.05$.

Table 2. Increase of MIF and absolute increase value in the FP and LP before and after 12-week resistance training

\begin{tabular}{llccc}
\hline & Testing & FP & LP & $P$-value \\
\hline MIF $(\mathrm{kg})$ & MIF & $76.18 \pm 13.61$ & $78.47 \pm 17.10$ & 0.083 \\
& MIF & $89.68 \pm 16.65$ & $92.60 \pm 16.38$ & $0.019^{*}$ \\
& $\Delta$ MIF & $13.49 \pm 9.68$ & $14.22 \pm 9.70$ & 0.691 \\
& $P$-value & $0.000^{*}$ & $0.000^{*}$ & \\
\hline
\end{tabular}

Values are presented as mean \pm standard deviation.

MIF, maximum isometric force; $F$, follicular phase; LP, luteal phase; pre, before training; post, after training; $\triangle \mathrm{MIF}$, absolute increase maximum isometric force.

${ }^{*} P<0.05$, statistically significant difference.

\section{RESULTS}

\section{Total data}

Total MIF was significantly increased both FP and LP after 12week resistance training. Total MIF was no significant different between FP and LP before training. However, we found that significant different between two phases after training and the absolute increase value was not significantly different between FP and LP (Table 2).

\section{Group data}

MIF in whole groups (BMI $\left.\mathrm{Buder}_{\text {und }}, \mathrm{BMI}_{\text {norm }}, \mathrm{BMI}_{\text {over }}\right)$ was no significantly different between FP and LP before training. MIF was significantly increased in whole groups $\left(\mathrm{BMI}_{\text {under, }}, \mathrm{BMI}_{\text {norm }}, \mathrm{BMI}_{\text {over }}\right)$ by FP and LP after training. Moreover, MIF after training and absolute increase value in $\mathrm{BMI}_{\text {norm }}$ and $\mathrm{BMI}_{\text {over }}$ were no significantly different between FP and LP. However, significant different of MIF after training and absolute increase value were found between FP and LP just by $\mathrm{BMI}_{\text {under }}$ (Table 3).

\section{DISCUSSION}

To the best of our knowledge, ours is the first study to examine the different effect of BMI on strength during the menstrual cycle. The main findings are that, first, total MIF was not signifi-

Table 3. Increase of MIF and absolute increase value in the FP and LP before and after 12-week resistance training among $\mathrm{BMI}_{\text {under, }}, \mathrm{BMI}_{\text {norm, }}$ and $\mathrm{BMI}_{\text {over }}$ groups

\begin{tabular}{llccc}
\hline Group & Testing & FP & LP & $P$-value \\
\hline BMlunder & MIF & $69.45 \pm 10.03$ & $68.92 \pm 9.68$ & 0.81 \\
& MIF & $79.08 \pm 11.60$ & $84.05 \pm 12.38$ & $0.01^{*}$ \\
& $\Delta \mathrm{MIF}$ & $9.63 \pm 5.47$ & $15.13 \pm 6.06$ & $0.05^{*}$ \\
& $P$-value & $0.002^{*}$ & $0.000^{*}$ & \\
BMI $_{\text {norm }}$ & MIF $_{\text {pre }}$ & $77.82 \pm 14.25$ & $79.94 \pm 19.56$ & 0.20 \\
& MIF $_{\text {post }}$ & $91.54 \pm 15.34$ & $94.09 \pm 16.35$ & 0.15 \\
& $\Delta$ MIF & $13.73 \pm 14.15$ & $14.15 \pm 9.57$ & 0.51 \\
& $P$-value & $0.000^{*}$ & $0.000^{*}$ & \\
BMI $_{\text {over }}$ & MIF & $86.51 \pm 10.07$ & $85.80 \pm 9.48$ & 0.82 \\
& MIF & $96.97 \pm 22.48$ & $99.03 \pm 19.12$ & 0.60 \\
& $\Delta M I F$ & $10.46 \pm 15.72$ & $13.23 \pm 14.84$ & 0.63 \\
& $P$-value & $0.050^{*}$ & $0.047^{*}$ &
\end{tabular}

Values are presented as mean \pm standard deviation.

$\mathrm{MIF}$, maximum isometric force; $\mathrm{FP}$, follicular phase; $\mathrm{LP}$, luteal phase; $\mathrm{BMI}$, body mass index; $\mathrm{BM}_{\text {under, }} \mathrm{BMl}<18.5 \mathrm{~kg} / \mathrm{m}^{2} ; \mathrm{BMI}_{\text {norm, }}, 18.5 \mathrm{~kg} / \mathrm{m}^{2} \leq \mathrm{BMl}<25 \mathrm{~kg} / \mathrm{m}^{2} ; \mathrm{BM}_{\text {over, }}$ $B M l \geq 25 \mathrm{~kg} / \mathrm{m}^{2}$; pre, before training; post, after training; $\Delta M \mathrm{MIF}$, absolute increase maximum isometric force.

${ }^{*} P<0.05$, statistically significant difference. 
cantly different between the FP and LP before training. However, we found that a significant difference between the two phases after training and the absolute increase value was not significantly different between the FP and LP. Second, MIF of all groups $\left(\mathrm{BMI}_{\text {under, }}\right.$, $\mathrm{BMI}_{\text {norm }}, \mathrm{BMI}_{\text {over }}$ ) was no significantly different between the $\mathrm{FP}$ and LP before training. MIF was significantly increased in all groups ( $\mathrm{BMI}_{\text {under }}, \mathrm{BMI}_{\text {norm }}, \mathrm{BMI}_{\text {over }}$ ) in the FP and LP. Finally, MIF after training and absolute increase value in $\mathrm{BMI}_{\text {norm }}$ and $\mathrm{BMI}_{\text {over }}$ were no significantly different between FP and LP. However, significant different of MIF after training and absolute increase value were found between $\mathrm{FP}$ and $\mathrm{LP}$ just by $\mathrm{BMI}_{\text {under. }}$.

Previous studies investigated the train of muscle strength with menstrual cycle-phased training. With regard to the menstrual cycle and muscle strength, previous studies found that the maximum strength increases during the FP and during ovulation (Phillips et al., 1996; Sarwar et al., 1996). For example, Sung et al. (2014) compared the effects of two different menstrual cycle-based leg strength training programs on muscle volume and microscopic morphological parameters. The authors suggested that the increase in MIF with FP-based training was higher than with the LP-based training; furthermore, the FP-based training was also associated with a higher increase in muscle diameter than the LP-based training. In addition, Sung et al. (2014) found significant positive effect in muscle fiber type 2 diameter and muscle cell nuclei-to-fiber ratio after the FP-based training, but not in the LP-based training. Therefore, the authors recommended that eumenorrheic females should base the periodization of their strength training on their menstrual cycle (Sung et al., 2014).

However, Greeves et al. (1997) reported the greatest strength during the mid-LP and suggested that progesterone may be implicated in the regulation of strength production. In a different study, Sakamaki-Sunaga et al. (2016) reported no major differences among different training frequencies for arm curls during menstrual cycle phases with regard to muscle hypertrophy and strength. The authors suggested that changes in female hormones caused by the menstrual cycle do not strongly affect muscle hypertrophy induced by resistance training (Sakamaki-Sunaga et al., 2016). Yet another study found no changes in strength, fatigue, and the twitch and tetanus characteristics throughout the menstrual cycle; the fluctuations in female reproductive hormones throughout the menstrual cycle were found to have no impact on muscle strength (Janse de Jonge, 2003). Consistently with the above-mentioned studies, there was no significant difference of absolute increase value between the FP and LP by $\mathrm{BMI}_{\text {norm }}$ and $\mathrm{BMI}_{\text {over }}$ groups, but absolute increase value was significantly dif- ferent between the FP and LP just by BMI $\mathrm{Bnder}_{\text {. }}$

To the best of our knowledge, this is the first study to show the relationship between different BMI level and muscle strength during the menstrual cycle. Our results demonstrate that MIF by just $\mathrm{BMI}_{\text {under }}$ group was significantly different between the FP and LP. Therefore, female athletes such as gymnasts or rhythmic gymnast with $\mathrm{BMI}_{\text {under, }}$ should consider a resistance training program on the day of their menstrual cycle. The main limitation of this study is that blood hormone concentrations were not measured and the sample size may have been small. Therefore, further larger-scale research is needed to replicate our results. In conclusion, the present study demonstrated that strength test must be considered of menstrual phase. Muscle strength must be tested in the same phase before and after training $\left(\mathrm{FP}_{\text {pre }}\right.$ and $\mathrm{FP}_{\text {post }}, \mathrm{LP}_{\text {pre }}$, and $\left.\mathrm{LP}_{\text {post }}\right)$ in all groups. In particular, we strongly recommend that female with $\mathrm{BMI}_{\text {under, }}$ such as athletes of gymnasts and rhythmic gymnasts, to consider strength test on day of their menstrual phase. In further studies, blood samples should be taken according to BMI levels for hormone profiling during the menstrual cycle.

\section{CONFLICT OF INTEREST}

No potential conflict of interest relevant to this article was reported.

\section{ACKNOWLEDGMENTS}

The authors thank all the participants which, without their help, we were not able to conduct the study.

\section{REFERENCES}

Albertson BD, Zinaman MJ. The prediction of ovulation and monitoring of the fertile period. Adv Contracept 1987;3:263-290.

Barros RP, Gustafsson JÅ. Estrogen receptors and the metabolic network. Cell Metab 2011;14:289-299.

Bruinvels G, Burden R, Brown N, Richards T, Pedlar C. The prevalence and impact of heavy menstrual bleeding among athletes and mass start runners of the 2015 London Marathon. Br J Sports Med 2016;50:566.

Constantini NW, Dubnov G, Lebrun CM. The menstrual cycle and sport performance. Clin Sports Med 2005;24:e51-82.

Costello JT, Bieuzen F, Bleakley CM. Where are all the female participants in Sports and Exercise Medicine research? Eur J Sport Sci 2014;14:847851.

de Mouzon J, Testart J, Lefevre B, Pouly JL, Frydman R. Time relationships 
between basal body temperature and ovulation or plasma progestins. Fertil Steril 1984;41:254-259.

Enea C, Boisseau N, Fargeas-Gluck MA, Diaz V, Dugué B. Circulating androgens in women: exercise-induced changes. Sports Med 2011;41:1-15.

Greeves JP, Cable NT, Luckas MJ, Reilly T, Biljan MM. Effects of acute changes in oestrogen on muscle function of the first dorsal interosseus muscle in humans. J Physiol 1997;500(Pt 1):265-270.

Greising SM, Baltgalvis KA, Lowe DA, Warren GL. Hormone therapy and skeletal muscle strength: a meta-analysis. J Gerontol A Biol Sci Med Sci 2009;64:1071-1081.

Hamadeh MJ, Devries MC, Tarnopolsky MA. Estrogen supplementation reduces whole body leucine and carbohydrate oxidation and increases lipid oxidation in men during endurance exercise. J Clin Endocrinol Metab 2005;90:3592-3599.

Hulens M, Vansant G, Lysens R, Claessens AL, Muls E, Brumagne S. Study of differences in peripheral muscle strength of lean versus obese women: an allometric approach. Int J Obes Relat Metab Disord 2001;25:676681.

Janse de Jonge XA. Effects of the menstrual cycle on exercise performance. Sports Med 2003;33:833-851.

Javed A, Tebben PJ, Fischer PR, Lteif AN. Female athlete triad and its components: toward improved screening and management. Mayo Clin Proc 2013;88:996-1009.

Kelly G. Body temperature variability (Part 1): a review of the history of body temperature and its variability due to site selection, biological rhythms, fitness, and aging. Altern Med Rev 2006;11:278-293.

Kraemer WJ, Ratamess NA. Hormonal responses and adaptations to resistance exercise and training. Sports Med 2005;35:339-361.

Kriengsinyos W, Wykes LJ, Goonewardene LA, Ball RO, Pencharz PB. Phase of menstrual cycle affects lysine requirement in healthy women. Am J Physiol Endocrinol Metab 2004;287:E489-496.

Lad UP, Satyanarayana P, Shisode-Lad S, Siri ChC, Kumari NR. A study on the correlation between the body mass index (BMI), the body fat percentage, the handgrip strength and the handgrip endurance in underweight, normal weight and overweight adolescents. J Clin Diagn Res 2013;7:51-54.

Lebrun CM. The effect of the phase of the menstrual cycle and the birth control pill on athletic performance. Clin Sports Med 1994;13:419-441.
Lowe DA, Baltgalvis KA, Greising SM. Mechanisms behind estrogen's beneficial effect on muscle strength in females. Exerc Sport Sci Rev 2010;38:61-67.

Mak KK, Ho SY, Lo WS, Thomas GN, McManus AM, Day JR, Lam TH. Health-related physical fitness and weight status in Hong Kong adolescents. BMC Public Health 2010;10:88.

Miller BF, Hansen M, Olesen JL, Flyvbjerg A, Schwarz P, Babraj JA, Smith K, Rennie MJ, Kjaer M. No effect of menstrual cycle on myofibrillar and connective tissue protein synthesis in contracting skeletal muscle. Am J Physiol Endocrinol Metab 2006;290:E163-168.

Owen JA Jr. Physiology of the menstrual cycle. Am J Clin Nutr 1975;28: 333-338.

Phillips SK, Sanderson AG, Birch K, Bruce SA, Woledge RC. Changes in maximal voluntary force of human adductor pollicis muscle during the menstrual cycle. J Physiol 1996;496(Pt 2):551-557.

Pieterse S, Manandhar M, Ismail S. The association between nutritional status and handgrip strength in older Rwandan refugees. Eur J Clin Nutr 2002;56:933-939.

Sakamaki-Sunaga M, Min S, Kamemoto K, Okamoto T. Effects of menstrual phase-dependent resistance training frequency on muscular hypertrophy and strength. J Strength Cond Res 2016;30:1727-1734.

Sarwar R, Niclos BB, Rutherford OM. Changes in muscle strength, relaxation rate and fatiguability during the human menstrual cycle. J Physiol 1996;493(Pt 1):267-272.

Sung E, Han A, Hinrichs T, Vorgerd M, Manchado C, Platen P. Effects of follicular versus luteal phase-based strength training in young women. Springerplus 2014;3:668.

Velders M, Schleipen B, Fritzemeier KH, Zierau O, Diel P. Selective estrogen receptor- $\beta$ activation stimulates skeletal muscle growth and regeneration. FASEB J 2012;26:1909-1920.

Wang N, Hikida RS, Staron RS, Simoneau JA. Muscle fiber types of women after resistance training--quantitative ultrastructure and enzyme activity. Pflugers Arch 1993;424:494-502.

Weigt C, Hertrampf T, Zoth N, Fritzemeier KH, Diel P. Impact of estradiol, ER subtype specific agonists and genistein on energy homeostasis in a rat model of nutrition induced obesity. Mol Cell Endocrinol 2012; 351:227-238. 